\title{
Automated train driver competency performance indicators using real train driving data
}

\author{
R.A.H. El Rashidy, P. Hughes, M. Figueres-Esteban \& C. van Gulijk \\ Institute of Railway Research, University of Huddersfield, Huddersfield, UK
}

\begin{abstract}
On Train Data Recorders (OTDR) are used within the GB Railways to collect data relating to train operations and the state of various train systems throughout a journey. These data include power and brake controller position and driver acknowledgement of signaling system warnings. This data could be used to assess driver competency but an assessment framework is required to extract the data sensibly. This paper proposes a train driver competency framework to define aspects that are related to train driver functions based on documents analysis, cab-rides and informal interviews. It also explores the utilization of OTDR in the quantification of the train driver competency framework by introducing a number of indicators under each aspect covered by the framework. The proposed indicators demonstrate to how OTDR data can be useful in routine systematic checks and pre-incident investigation, for example, identification of the deviation from recommended rules that may have safety implications. Furthermore, the data may allow for improved understanding of driver performance that in turn could allow the development of more effective safety management strategies. A number of numerical example presented to illustrate applicability of developed algorithm.
\end{abstract}

\section{INTRODUCTION}

On train data recorder (OTDR) offers an opportunity to understand the driver use of power, brake and safety systems during a journey. Despite the potential of OTDR data, it is not widely used to facilitate the automatic analysis of driver performance.

This paper presents a train driver competency framework based on official documents and reflecting the professional driving policies. It will also explore the use of OTDR data to quantify different areas covered by the proposed train driver competency framework to assess train driver performance aspects such as drivers' use of safety systems and braking, in addition, to derive indicators to measure the vigilance level of a driver.

\section{AUTOMATED SAFETY ASSESSMENT}

In the UK, current practice for assessing driver competence performance is in-cab riding by driver managers. A number of train operating companies use in-cab assessment to monitor drivers' operational usage of Driver's Reminder Appliance (DRA) (McCorquodale et al., 2002). In some cases, digital cameras implemented to record driver's action but they tend to be unpopular (RSSB, 2004). These techniques have their merits in assessing the driver performance as they supplied com- prehensive details about the driver's behavior. However, drivers may behave differently under observation, limiting the potential for independent driver assessment. Add to that, the time and cost traditional methods hinder their use for continuous monitoring.

A number of research studies (Balfe, 2016; El Rashidy \& Van Gulijk, 2016; Walker \& Strathie, 2014; Green et al., 2011) explored the advantage of using OTDR source in different areas such as station duties, driver assessment and interaction with warning systems. Green et al. (2011) introduced a number of indicators to assess driver performance. They are:

- The speed at which power Notch 4 (out of a total of 4 notches) is selected when accelerating;

- The percentage of time in a braking sequence that the driver selects brake step 3 (out of a total of 4 steps);

- The of the train as it traverses a Train Protection and Warning System grid (TPWS) approaching a Permanent Speed Restriction (PSR);

- The speed through a PSR as a percentage of the maximum speed and the mean speed when the warning system (AWS) horn is received.

- Erroneous events such as wrong-side door release and system trips such as TPWS brake demand.

These indicators are compared with the average performance of the whole population of train drivers 
to assess an individual's driving performance in relation to the cohort of drivers. The study introduced initial learning OTDR analysis but did not make use of all the available OTDR that related to the driver performance.

The aim of this paper is similar to the papers above: to assess driver performance in relation to safe driving of a train but we propose a more comprehensive framework.

\section{METHOD}

The method proposed in this work comprises of two steps, viz. developing a train driver competency framework and introducing a number of performance indicators to quantify elements of the framework using OTDR data.

\subsection{Train driver competency framework}

The framework is based on documents analysis, cab-rides and interviews.

Document analysis clarified the driver function and best practices in relation safe professional driving. For example, the professional driving policy (e.g. SWT, 2012; LM, 2009) was used to identify the recommended travel speed when approaching a red aspect and braking rules. The Rule Book - Train Driver Manual (GE/RM8000/ train driver) was also used to identify rules that the driver should comply with such as the use of safety systems.

To gain more knowledge about the driver environment and driver reaction under different situations, cab-rides were carried out. In addition, consultations, in the form of informal interviews, with a driver and a driver manager were conducted to discuss some operational issues and clarify some technical points.

Based on above processes the following aspects were identified:

- The driver handling of trains;

- The driver's compliance with rules;

- The driver's vigilance;

Under each aspect, a number of indicators were introduced, as presented in Figure 1, to facilitate the conversion of the conceptual framework to operational indicators that can be used to assess each aspect. Train handling aspect covers how the driver uses the brake system and the power system whereas compliance deals with rules in relation to driver's handling safety systems. The vigilance level of the driver has been assessed by a number of TPWS brake demands, wrong-side door release and percentage of instant cancellations of AWS horn.

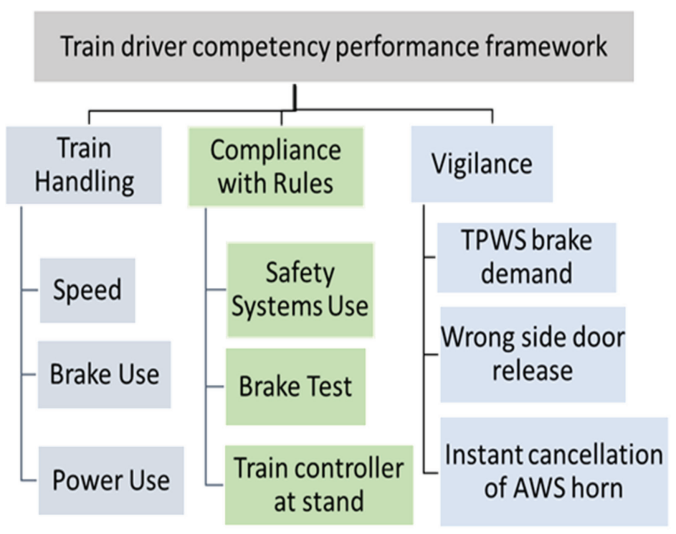

Figure 1. Train driver competency framework.

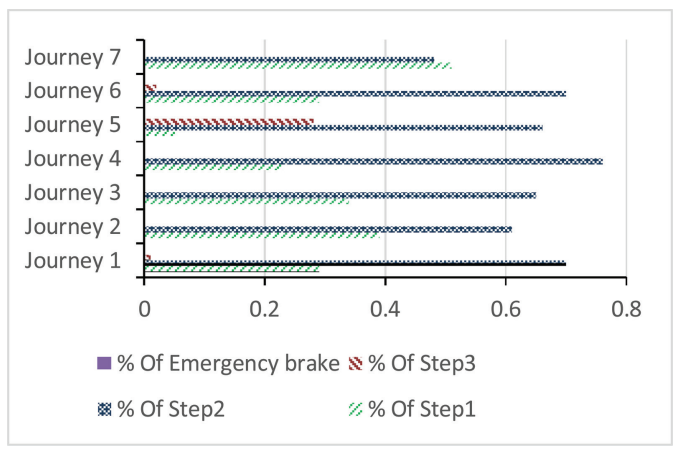

Figure 2. Brake use for a pair of origin-destination pair.

\subsection{Train driver performance indicators}

A bottom-up approach was implemented to develop train driver competency performance indicators (DCPIs) based on driver competency framework using OTDR data.

\subsubsection{OTDR data}

The OTDR data files used in this paper were supplied by Southern Railway. They are for the same route and the same day but different drivers to eliminate the impact of route conditions.

\subsubsection{Initial data handling}

The initial data handling process, presented in Figure 2, includes a number of steps as follows:

- Examine data types and format and correct them if needed. For example, the format of a relative journey time is converted from " $+01 \mathrm{~h} 24 \mathrm{mn} 26 \mathrm{~s}$ 6 " to "5066.6" seconds.

- Compress all variables that occurred at the same time in a single data row. Closer inspection of the 
data showed a relative journey time record may appear more than once with different groups of variables (i.e. for the same time record, there was more than one input line from different data channels).

- Processing missing data using different logical processes, for example, filling the missing values of train distance with calculated distance based on the available time duration and train speed. This error checking is specific to the Class 455 data used in this study, although it is likely that all OTDR data will need similar error handling and cleaning routines to make it useable.

After this pre-processing, data analysis could commence.

\subsubsection{Detection algorithms}

A number of algorithms have been developed in the $\mathrm{R}$ software package to extract relevant indicators for each behavior aspect presented in Figure 1.

\subsubsection{Data analysis}

A number of algorithms have been developed in $\mathrm{R}$ to identify relevant scenarios for each behavior aspect presented in Figure 1 and, then, calculate the metric. The metrics are mostly the frequency, the averaging or maximum or minimum values. A number of standard statistical visualizations were used to present the results such as boxplots.

\section{RESULTS}

\subsection{Proposed DCPIs}

Table $1 \mathrm{a}, \mathrm{b}$ and c summarize DCPIs that developed in this work and shows the proposed performance metric and criteria for each indicator assessment.

\subsection{Safety related DCPIs examples}

This section gives a few numerical examples of DCPIs that can be related to safety rules or devices to illustrate the use of OTDR rather than detecting any trend or best practice rule due to the size of the used data sample.

Under the train handling aspect, braking behavior and speed at AWS horn approaching a red aspect are presented here as they are directly related to safety. For braking behavior, Figure 2 shows the percentage of each brake step use calculated by considering the travelled distance using each step. For example, in "Journey 5" the driver applied Step $2(0.66)$ in addition to using Step $3(0.28)$ as shown in Figure 2 due to the late use of the brake which may create a hazard condition under different circumstance such as low adhesive condition. It should be noted that use of brake Step 3 should be
Table 1. DCPIs based on OTDR data.

(a) Train handling

\begin{tabular}{|c|c|}
\hline Aspect & Metric \\
\hline Braking behavior. & $\begin{array}{l}\text { Pattern recognition based } \\
\text { on braking curve data }\end{array}$ \\
\hline $\begin{array}{l}\text { Use of brake-step } 3 \text { on } \\
\text { approach to stations. }\end{array}$ & $\begin{array}{l}\text { The maximum percentage } \\
\text { of distance travelled } \\
\text { using } \\
\text { brake-step } 3 \text { per station } \\
\text { during a journey. }\end{array}$ \\
\hline $\begin{array}{l}\text { Use of brake on } \\
\text { approach to stations. }\end{array}$ & $\begin{array}{l}\text { The percentage distance } \\
\text { travelled using each } \\
\text { brake-step. }\end{array}$ \\
\hline Speed & $\begin{array}{l}\text { The speed at AWS horn } \\
\text { (mph) prior to a red } \\
\text { aspect } \\
\text { The frequency of train } \\
\text { speed }<=3 \mathrm{mph} \text { when } \\
\text { power Notch } 4 \text { selected } \\
\text { during the journey }\end{array}$ \\
\hline Use of power. & $\begin{array}{l}\text { The percentage of distance } \\
\text { travelled using power } \\
\text { notches } 1 \text { to } 4 \text { (out of } 4 \text { ). }\end{array}$ \\
\hline
\end{tabular}

*AWS stand for Automatic Warning System.

(b) Compliance with rules

\begin{tabular}{|c|c|}
\hline Aspect & Metric \\
\hline Use of EBS* & EBS operated event, \\
\hline Use of TPWS* & TPWS isolated events, \\
\hline $\begin{array}{l}\text { Use of DRA* in front of a } \\
\text { red aspect. }\end{array}$ & $\begin{array}{l}\text { The number of DRA } \\
\text { operated event }\end{array}$ \\
\hline $\begin{array}{l}\text { Use of DRA at the start of } \\
\text { a journey }\end{array}$ & $\begin{array}{l}\text { comparing with, a } \\
\text { number of red aspects }\end{array}$ \\
\hline $\begin{array}{l}\text { Use of DRA during } \\
\text { the coupling/ } \\
\text { uncoupling activity }\end{array}$ & the driver experienced. \\
\hline $\begin{array}{l}\text { Putting the brake } \\
\text { controller into Step } \\
3 \text { once the train is at } \\
\text { Stand. }\end{array}$ & $\begin{array}{l}\text { Number of Step } 3 \text { at stand } \\
\text { compared with number } \\
\text { of station and red aspect } \\
\text { during a journey }\end{array}$ \\
\hline $\begin{array}{l}\text { Brake test before the first } \\
\text { station and the first } \\
\text { caution aspect. }\end{array}$ & $\begin{array}{l}\text { The use of brake prior to } \\
\text { the first station or an } \\
\text { AWS horn. }\end{array}$ \\
\hline
\end{tabular}

*EBS, TPWS and DRA stand for Emergency Bypass Switch, Train Protection and Warning System, and Driver's Reminder Appliance, respectively.

(c) Vigilance

\begin{tabular}{lc}
\hline Aspect & Metric \\
\hline $\begin{array}{l}\text { Instant cancellation of } \\
\text { AWS horn }\end{array}$ & $\begin{array}{c}\text { The percentage of instant } \\
\text { AWS cancellation }\end{array}$ \\
$\begin{array}{l}\text { Wrong side door release } \\
\text { Number of wrong side door } \\
\text { release }\end{array}$ \\
$\begin{array}{c}\text { NPWS Demand } \\
\text { application }\end{array}$ & application \\
\hline
\end{tabular}


minimized, as a good practice unless the driver had to use it due to low track adhesion.

For the speed, Table 2 presents the speed at AWS horn when the driver approaching a red aspect. A higher than normal speed when approaching a red aspect may cause a SPAD (signal passed at dangerous without authorization) or lead to a full brake application to stop the train at the correct location. For one train operator this is 20 meters in advance of the red aspect (LM, 2009). For the OTDR sample used in this paper all driver complied with this rule as showed in Table 2.

Under compliance with rules, braking test is checked as the brake test enables the driver to evaluate the performance of train braking system prior to the need to use it. Using OTDR data enables checking this rule prior to the driver first stop (due to a station or a red aspect). For example, Figure 3 shows that the driver carried out the brake test prior to the first AWS horn, in contrast, the driver presented by first AWS horn.

For vigilance aspect, wrong-side door release is presented. Releasing the doors on the wrong side of the train may have serious consequences as it could cause a potential harm to railway passengers. Only one of the journeys showed any instances that appeared to have wrong-side door release. This journey is shown in Figure 5 and is unusual in that the train appears to be stationary for most of the time. It is possible that this file shows a train under maintenance. Figure 5 shows door releases; on each occasion the right-hand side door (shown by the blue circles) is released shortly before the left-hand side door (shown by the red line). Because of the very short period between the two door releases, they appear to occur at the same time in the figure. Whilst this file does not appear to show an instance of an actual hazard - since the train did not appear to be moving - it nevertheless demonstrates that it is possible to use OTDR data to detect instances of wrong-side door release.

Table 2. Maximum speed at AWS horn prior to red aspect.

\begin{tabular}{lll}
\hline $\begin{array}{l}\text { Journey } \\
\text { Number }\end{array}$ & $\begin{array}{l}\text { Number of } \\
\text { red aspects }\end{array}$ & $\begin{array}{l}\text { Maximum train } \\
\text { Speed approaching } \\
\text { a red aspect }\end{array}$ \\
\hline Journey 1 & 0 & NA* \\
Journey 2 & 2 & 11 \\
Journey 3 & 1 & 14 \\
Journey 4 & 1 & 11 \\
Journey 5 & 1 & 14 \\
Journey 6 & 2 & 13 \\
Journey 7 & 1 & 14 \\
\hline
\end{tabular}

*The driver did not have any red aspect signal during his/ her journey

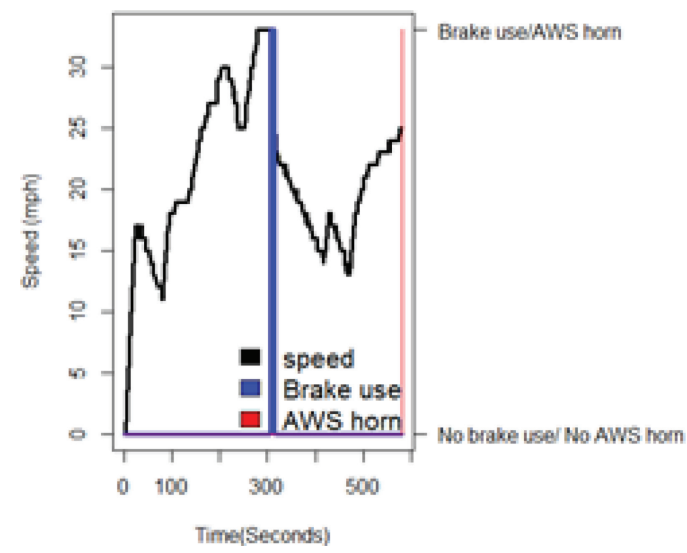

Figure 3. Brake test before stopping prior to the first AWS horn.

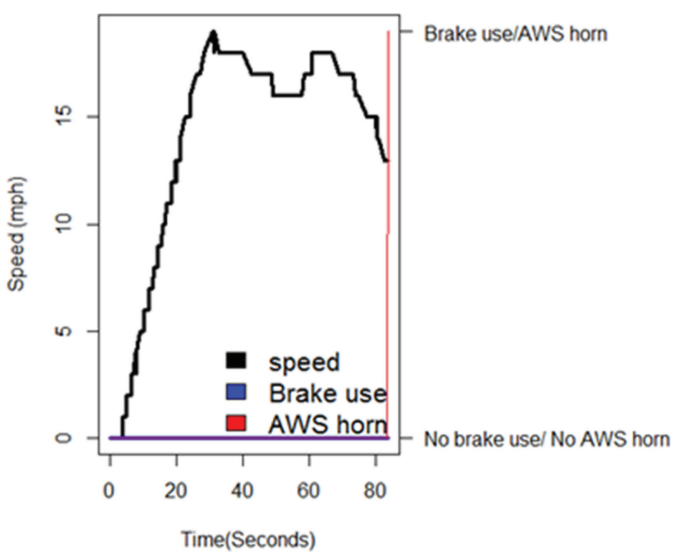

Figure 4. No brake test before stopping prior to the.

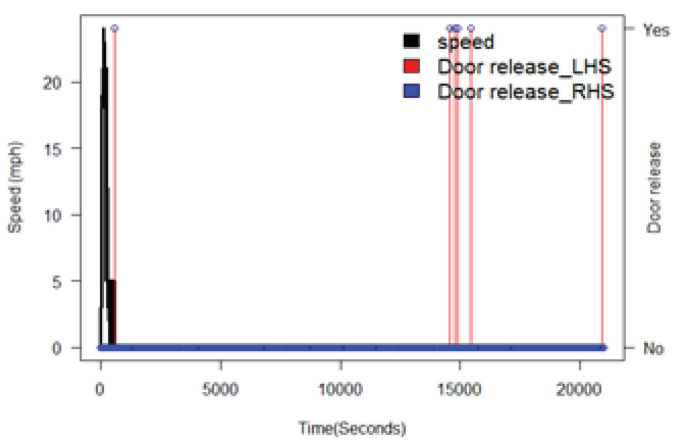

Figure 5. Wrong side door release.

\section{DISCUSSION}

Considering the growing interest in harvesting data sources such as OTDR, the development of DCPIs 
that support that direction is essential. DCPIs proposed in this paper developed not only based the available data from OTDR but also supported by the official documents such as Rule Book and number of professional driving policy documents.

The technological approach described offers sensible solutions for the extraction of DCPIs from OTDR; it offers rapid analysis of the driver performance in contrast to in-cab-riding assessment by a driver manager that normally takes place every six months and only provides the opportunity for a driver to be assessed under a limited range of conditions. Furthermore, the in-cab-riding assessment may cause drivers to behave differently under observation, whilst DCPIs can be calculated without disrupting the driver.

DCPIs do not pass judgement about what is 'good' or 'bad' but illustrate how data is extracted in a sensible way from a huge dataset. For qualitative judgement, the allocation of indicators may need further discussion in the implementation stage to consider related parties point of view.

A few numerical examples of DCPIs are presented to illustrate the practicality of using OTDR to calculated DCPIs. However, the used data sample was very small to detect any trend or best practice rule.

\section{CONCLUSION}

In this paper, the train driver competency framework was introduced to outline the main areas of a driver function using documentary analysis (e.g. TOCs professional driving policy and the Rule Book), in addition to interviews and in cab-rides. A number of DCPIs have also proposed to assess driver performance under real-life conditions using OTDR data.

OTDR offers great sources to develop a comprehensive list of behavior aspects related to driver performance that can be determined from OTDR data.

\section{REFERENCES}

Balfe, N. 2017. A framework for human factors analysis of railway on-train data. In D. de Waard, A. Toffetti, R. Wiczorek, A. Sonderegger, S. Röttger, P., Bouchner, T. Franke, S. Fairclough, Noordzij, M. \& Brookhuis, K. (Eds.) (2017). Proceedings of the Human Factors and Ergonomics Society Europe Chapter 2016 Annual Conference. ISSN 2333-4959 (online). Available from http://hfes-europe.org

El Rashidy, R. \& Van Gulijk, C. 2016. Driver competence performance indicators using OTMR. In Proceedings of CIT2016 Congreso de Ingeniería del Transporte (XII Congress of Transport Engineering, pp. 354-361.

Green, S.R.\& Barkby, S. \& Puttock, A. \& Craggs, R. 2001. Automatically assessing driver performance using black box OTDR data. Railway Condition Monitoring and Non-Destructive Testing ( RCM 2011), 5th IET Conference, pp.1-5, 29-30 Nov. 2001.

HAS, The Health and Safety Authority, 2013. Behaviour based safety guide: doing what we do better, smarter, safer. HAS, the Health and Safety Authority, Dublin.

London Midland, LM. 2009. Professional driving policy.

McCorquodale, B. \& Chissick, C. \& McGuffog, A., Rowley, I. Bunting, A. \& Page, H. 2002. Driver's Reminder Appliance (DRA) effectiveness study: Final report, Qinetiq/KI/CHS/CAP/CR020937/2.0/2.0, QinetiQ, Farn-borough.

Mcleod, R. \& Walker, G.H. \& Moray, N. \& Love, G. 2003. Driver reliability with extended AWS. Project Summary Report. B/C271/FD.5. Nickleby HFE Ltd.

RSSB. 2004. The Rail Safety and Standards Board, Driver Error Data Collection Project: Final Report, RSSB.

RSSB. 2015. Guidance on Defective On-Train Equipment. Retrieved March 8, 2016, from: https://www rssb.co.uk/rgs/standards/GOGN3637\%20Iss\%202. pdf.

Rule Book. 2015. Train Driver Manual. Retrieved March 8, 2016,from: https://www.rssb.co.uk/rgs/rulebooks/ GERM8000-traindriver $\% 201$ ss $\% 202$.pdf.

South West Trains, LM. 2012. Professional driving policy and braking instructions. 7, South West Trains. 